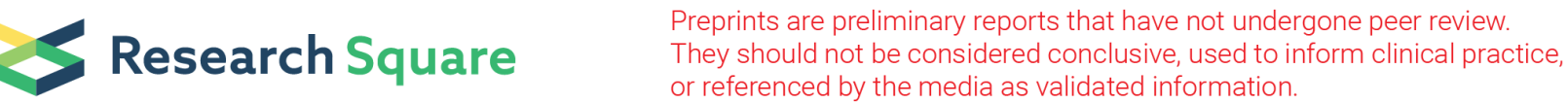

\section{Prevalence and cardiovascular risk factors of carotid plaque in rural-dwelling adults: a population- based study in Shandong, China}

\section{Jie Zhang}

Shandong Provincial Hospital Affiliated to Shandong First Medical University

\section{Yuanyuan Xiang}

Shandong Provincial Hospital Affiliated to Shandong First Medical University

Xiaokang Ji

Shandong University School of Public Health

\section{Shaowei Sang}

Shandong University Qilu Hospital

\section{Sai Shao}

Shandong Medical Imaging Research Institute

\section{Xiang Wang}

Shandong Provincial Hospital Affiliated to Shandong First Medical University

\section{Xiaohui Liu}

Shandong Provincial Hospital Affiliated to Shandong First Medical University

\section{Guangbin Wang}

Shandong Medical Imaging Research Institute

\section{Ming Lv}

Shandong University Qilu Hospital

\section{Fuzhong Xue}

Shandong University School of Public Health

\section{Yifeng Du}

Shandong Provincial Hospital Affiliated to Shandong First Medical University

QinJian Sun ( $\nabla$ sqi1210@163.com )

Shandong Provincial Hospital https://orcid.org/0000-0002-9323-9154

\section{Research article}

Keywords: Carotid, Atherosclerotic, Plaque, Ultrasonography, Cardiovascular risk factors

Posted Date: February 25th, 2021

DOl: https://doi.org/10.21203/rs.3.rs-258874/v1 
License: (c) (i) This work is licensed under a Creative Commons Attribution 4.0 International License. Read Full License 


\section{Abstract \\ Background}

The association between carotid plaque (CP) and cardiovascular risk factors (CRFs) remains elusive. And few studies focus on CRFs associated with multiple CPs and irregular CP. We aimed to investigate CRFs associated with the presence, number and irregular surface morphology of $\mathrm{CP}$ in rural-dwelling Chinese population.

\section{Methods}

This population-based study included 2021 participants who were aged $\geq 40$ and free of stroke. Data were collected via interviews, clinical examinations, and laboratory tests. Carotid plaque was estimated by ultrasonography. Binary logistic and multinomial logistic regression models were used to analyze data.

\section{Results}

Of the 2021 participants, 774 (38.3\%) were detected with CP. The multi-adjusted odds ratio (95\% confidence interval) of CP was 1.75 (1.40-2.19) for hypertension, 1.62 (1.03-2.55) for low high-density lipoprotein cholesterol (HDL-C), 1.55 (1.20-2.01) for high hypersensitive C-reactive protein (hs-CRP), 1.41 (1.07-1.87) for diabetes mellitus (DM), 1.39 (1.00-1.93) for high total cholesterol and 1.38 (1.03-1.85) for high low-density lipoprotein cholesterol (LDL-C). When the number and surface morphology of CP were analyzed, hypertension, high hs-CRP, DM and high LDL-C were associated with multiple CPs; hypertension, high hs-CRP and high total cholesterol were associated with irregular CP.

\section{Conclusions}

Carotid plaque is common amongst middle-aged and older people living in rural China. Hypertension, low HDL-C, high hs-CRP, DM, high total cholesterol and high LDL-C may be associated independently with CP.

\section{Background}

Carotid plaque (CP) is associated with an increased risk of ischemic stroke, which is a major cause of human death and long-term disability $[1,2]$. Previous studies indicated that CP was highly prevalent in China, approximately $40.3 \%-60.3 \%$ of Chinese aged $\geq 40$ years were affected [3-5], and more than $70 \%$ of CP occurred in rural areas [6]. With demographic ageing, the number of individuals with CP will further increase, which might be indicative of considerable burden of ischemic stroke in the future. Compared with carotid intima-media thickening, CP assessed by ultrasound is a stronger and more accurate 
predictor of ischemic stroke [1]. Therefore, identifying the modified cardiovascular risk factors (CRFs) associated with $\mathrm{CP}$ is essential for the prevention and treatment of ischemic stroke.

The CRFs associated with CP have been explored by previous studies, but association between CP and CRFs remains elusive $[7,8]$. However, few studies have focused on the correlation between CRFs and CP characteristics such as number and surface irregularity, which increase the risk of cardio-cerebrovascular disease $[2,9]$.

Therefore, this study aimed to investigate the CRFs associated with the presence, number and surface morphology of CP in middle-aged and older adults living in rural communities in China.

\section{Methods}

\section{Study design and population}

This study was based on the Kongcun Town Asymptomatic Intracranial Artery Stenosis study, which has been described previously in detail $[10,11]$. Briefly, this is an ongoing, population-based study targeting a total of 2311 rural residents aged $\geq 40$ years and with no history of stroke. Of the 2311 participants, 2027 completed questionnaires [11], laboratory blood tests and imaging examinations. In this study, 6 participants were excluded due to missing information on smoking habits $(n=5)$ and drinking habits $(n=1)$. Finally, the data of 2021 eligible participants were analyzed. Due to the missing information for surface morphology $(n=21)$ and the number $(n=7)$ of CP, 2000 and 2014 participants were involved in the analysis, respectively.

\section{Collection and Assessment of variables}

As previous described $[10,11]$, data on demographics, CRFs, medical history, anthropometrics and blood biochemical markers were collected. Hypertension was defined as blood pressure $\geq 140 / 90 \mathrm{mmHg}$, use of antihypertensive drugs, or self-reported hypertension. Diabetes mellitus (DM) was defined as fasting plasma glucose $\geq 7.0 \mathrm{mmol} / \mathrm{L}$, use of blood glucose-lowering drugs, insulin injection or self-reported history of diabetes. Dyslipidemia was defined as total cholesterol $\geq 6.20 \mathrm{mmol} / \mathrm{L}$ or triglyceride $\geq 1.80$ $\mathrm{mmol} / \mathrm{L}$ or high-density lipoprotein-cholesterol $(\mathrm{HDL}-\mathrm{C})<1.11 \mathrm{mmol} / \mathrm{L}$ or low-density lipoproteincholesterol $(\mathrm{LDL}-\mathrm{C}) \geq 3.36 \mathrm{mmol} / \mathrm{L}$, or use of cholesterol-lowering medication or self-reported hyperlipidemia. Smoking habits were defined as consuming at least one cigarette per day for more than one year and were dichotomized as never vs. ever. Alcohol intaking habits were defined as drinking at least once a week for more than 6 months, and were categorized as never vs. ever.

\section{Carotid ultrasonography examination}

Carotid plaque was detected by ultrasonography examination which has been proved to have high sensitivity and specificity [12]. The measurement and assessment of CP have been described in detail previously [11]. Carotid plaque was defined as focal intimal-middle film thickness $\geq 1.5 \mathrm{~mm}$ [13]. The surface morphology and number of CP were also observed by two experienced physicians through 
ultrasonography, and $\mathrm{CP}$ was divided into regular $\mathrm{CP}$ group and irregular $\mathrm{CP}$ group according to the surface morphology.

\section{Statistical analysis}

All statistical analyses were performed using the Statistical Package for the Social Sciences software version 22.0 for Windows (IBM Corp., Released 2013, Armonk, NY: IBM Corp). Demographic and clinical information of participants were presented as mean (standard deviation) for continuous variables and frequency (\%) for categorical variables. Differences between participants with and without CP were compared using t-test for continuous variables and the chi-squared test for categorical variables. Binary logistic and multinomial logistic regression models were used to estimate the odds ratio and $95 \%$ confidence interval of the related CRFs for the presence, surface morphology and number of CP. The variables included in multiple-adjusted model were age, gender, hypertension, DM, total cholesterol, triglyceride, LDL-C, HDL-C, hypersensitive C-reactive protein (hs-CRP), body mass index (BMI), smoking habits, alcohol intaking habits. All statistical tests were two-tailed, and the significance level was set at $p<0.05$.

\section{Results}

\section{Characteristics of study participants}

Demographic and clinical characteristics of study participants are shown in (Table 1). Of the 2021 participants, 774 (38.3\%) suffered from CP. Compared with participants without CP, participants with CP were older and had higher levels of total cholesterol, triglyceride, LDL-C, BMI and hs-CRP. In addition, participants with CP were also more likely to suffer from hypertension, DM and dyslipidaemia. Moreover, the proportion of smokers and drinkers was significantly higher in participants with $\mathrm{CP}$ than in those without $\mathrm{CP}$.

\section{Association between CRFs and CP}

Hypertension, DM, high total cholesterol ( $\geq 6.20 \mathrm{mmol} / \mathrm{L})$, high LDL-C $(\geq 3.36 \mathrm{mmol} / \mathrm{L})$, low HDL-C $(<1.11$ $\mathrm{mmol} / \mathrm{L})$ and high hs-CRP ( $\geq 2.00 \mathrm{mg} / \mathrm{L}$ ) were significantly associated with an increased odds ratio of $\mathrm{CP}$, even when multiple potential confounders were controlled (Table 2). After adjusting for multiple potential confounders, hypertension, DM, high LDL-C and high hs-CRP were significantly associated with an increased likelihood of multiple CPs (Table 3). In the multiple-adjusted model, hypertension, high total cholesterol and high hs-CRP were associated with an increased likelihood of irregular CP (Table 4).

\section{Discussion}

In this population-based study, we found that the prevalence of CP was 38.3\% among rural-dwelling adults aged $\geq 40$ years in Shandong China. Hypertension, DM, high total cholesterol, high LDL-C, high hsCRP and low HDL-C were positively associated with the presence of CP. Moreover, hypertension, DM, high 
LDL-C and high hs-CRP were associated with multiple CPs; hypertension, high total cholesterol and high hs-CRP were associated with irregular CP.

Previous population-based cohort studies have showed the prevalence of CP in different areas. The Tromso study found that the prevalence of CP was $35 \%$ in men and $27 \%$ in women among inhabitants aged 40 to 87 years in Northern Norway [14]. In the Northern Manhattan Study, the prevalence of CP among participants $\geq 39$ years of age was 57\% [15]. In China, the Asymptomatic Polyvascular Abnormalities Community study found that the prevalence of CP was $54.1 \%$ among inhabitants $\geq 40$ years of age in Tangshan city [4] and another study found that the prevalence of CP was $40.3 \%$ among inhabitants $\geq 45$ years old in Tianjin city [3]. Although previous studies indicated that extracranial atherosclerosis was more common in white patients compared with Asians $[16,17]$, the above three studies conducted in China suggested that $\mathrm{CP}$ was more common in Chinese. Therefore, identifying the modified CRFs associated with CP is essential for the future prevention and treatment of ischemic stroke in China.

This study found that DM was associated with the presence of CP and multiple CPs, which was consistent with previous studies $[3,18,19]$. The underlying mechanisms of the correlation between diabetes and carotid atherosclerosis may be explained by the decrease in the bioavailability of the main anti-atherosclerotic factor endothelium-derived nitric oxide [20], and abnormal platelet activity caused by insulin insufficient and/or resistance [21].

In this study, we found that the association of hypertension with the presence of CP and multiple CPS, which was consistent with previous studies $[18,19]$. Previous studies have shown that hypertension may be the most prominent risk factor for carotid atherosclerosis $[22,23]$. The association between hypertension and surface morphology of CP was also examined by our study. The present study found that hypertension was not only related to regular CP, but also to irregular CP. Hypertension increases the pulling stress imposed on the carotid artery. Some studies found that the carotid artery wall material of hypertensive patients was less elastic at the site of the plaque than upstream and in the area affected by plaque, carotid artery was strained inwardly, which may generate a high level of stress concentrations and fatigue [24], leading to plaque rupture and irregular plaque surface formation. In addition, a four-year follow-up study suggested that hypertension was associated with new intraplaque hemorrhage [25], which was found to co-exist with disruption of the plaque surface [26].

Some studies have examined the association between lipid profiles and CP, but got inconsistent results $[19,27-29]$. High LDL-C was found to be associated with the presence of CP [19, 27, 29], which was consistent with our findings. However, an Algeria study failed to prove the association between high LDL$\mathrm{C}$ and CP [28]. In this study, high LDL-C was also found to be related to multiple CPs, which was in line with a previous study [19]. Consistent with other previous studies [28, 29], low HDL-C was also associated with $\mathrm{CP}$ in the present study, which suggested that HDL-C may be a protective factor for carotid atherosclerosis. It is worth noting that in this study, high total cholesterol was not only associated with the presence of $\mathrm{CP}$, but also with irregular $\mathrm{CP}$. The relationship between total cholesterol and the presence 
of CP also has been found in some studies [27, 30]. To our knowledge, the association between total cholesterol and the surface morphology of CP has not been studied yet. Plasma cholesterol was considered to be the most important determinant of the putatively thrombogenic lipid core, thus high total cholesterol may be related to the rupture proneness of atherosclerotic lesions [25, 31], which may explain the association between total cholesterol and irregular CP.

Consistent with previous studies [32-34], we found that high hs-CRP was associated with the presence of CP. Moreover, the association of hs-CRP with multiple CPs or irregular CP were also found in the present study. Hs-CRP, a clinical marker of inflammation, is mainly produced by hepatocytes in response to increased interleukin-6 [35]. Previous studies indicated that hs-CRP may participate in the pathogenesis of atherosclerosis, including promoting vascular remodeling, endothelial cell dysfunction [36] and lowdensity lipoprotein cholesterol deposition [37]. The underlying mechanism of the association between hs$\mathrm{CRP}$ and $\mathrm{CP}$ is still elvsive. Some studies indicated that CRP levels were positively associated with the number of new vessels in the plaque [38], and new microvessels at the base of the plaque are independently associated with plaque rupture [39], which may partly explain the relationship between hsCRP and CP with irregular surface.

To our knowledge, this is the first study not only to explore the CRFs associated with the presence of CP, but also to investigate the CRFs associated with multiple CPs and irregular CP, which may increase the risk of ischemic stroke [2, 9]. Secondly, we used ultrasound to examine the plaques, which may be less accurate than magnetic resonance imaging (MRI) or computed tomography (CT). However, a study on the accuracy of ultrasound, CT and MRI in the diagnosis of CP morphology found that ultrasound had higher accuracy for the diagnosis of CP morphology than that of CT or MRI [12]. In addition, compared to CT or MRI, ultrasound is non-invasive, easily available and inexpensive. Thirdly, compared with the city dwellers, rural populations receive fewer medical interventions due to the backward economic and medical level, which provides more accurate information for carotid atherosclerosis.

However, there are several limitations in the present study. Firstly, this study is an ongoing cohort study, it is impossible to make causal conclusions. Secondly, this study was conducted on the middle-aged and elderly populations living in China rural area. Therefore, caution should be taken when generalizing our findings to other ethnical groups.

\section{Conclusions}

This study suggested that hypertension, DM, high total cholesterol, high LDL-C, high hs-CRP and low HDL$\mathrm{C}$ may be independently associated with the presence of CP. Moreover, hypertension, DM, LDL-C and hsCRP might be associated with multiple CPs, and hypertension, total cholesterol and hs-CRP might be associated with irregular $\mathrm{CP}$.

\section{Abbreviations}


$\mathrm{BMI}$, body mass index; $\mathrm{CP}$, carotid plaque; CT, computed tomography; DM, Diabetes mellitus; HDL-C, highdensity lipoprotein cholesterol; hs-CRP, hypersensitive C-reactive protein; LDL-C, low-density lipoprotein cholesterol; MRI, magnetic resonance imaging.

\section{Declarations}

\section{Ethics approval and consent to participate}

The Ethics Committee of the Shandong Provincial Hospital affiliated to Shandong First Medical University approved the study protocol, and the study was conducted in accordance with the Declaration of Helsinki. Written informed consent was obtained from all participants.

\section{Consent for publication}

All participants provided their informed consent.

\section{Availability of data and materials}

The datasets obtained during this study are available from the corresponding author on reasonable request.

\section{Competing interests}

The authors declare that they have no competing interests.

\section{Funding}

This Study was supported by the grants from Jinan Science and Technology Bureau (201704101), Department of Science and Technology of Shandong Province (2014GSF118106, 2016GSF201062, and ZR2017MH114), the National Nature Science Foundation of China $(8171101298,81971128)$, and the China Ministry of Sciences and Technology (2017YFC1310100 and 2017YFC0907003). The funding agency played no role in the conception and design of the study, data collection, analysis and interpretation, and manuscript writing.

\section{Authors' contributions}

QJS, YFD and FZX conceived and designed the research. JZ, YYX, XW, XKJ, SWS, SS, and XHL acquired the data. YYX, WX, SS, XHL and GBW analyzed and interpreted the data. JZ and YYX draft the manuscript. XW, ML, FZX, YFD and QJS made critical revisions of the manuscript. All authors approved the final manuscript.

\section{Acknowledgements}

We would like to thank all the study participants, staff of the participating hospitals, and the Steering Committee Members of this study. 
Author details

${ }^{1}$ Department of Neurology, Shandong Provincial Hospital Affiliated to Shandong First Medical University, Jinan, Shandong, China. ${ }^{2}$ Department of Biostatistics, School of Public Health, Shandong University, Jinan, Shandong, China. ${ }^{3}$ Department of Clinical Epidemiology, Qilu Hospital, Cheeloo College of Medicine, Shandong University, Jinan, Shandong, China. ${ }^{4}$ Department of Radiology, Shandong Medical Imaging Research Institute, Cheeloo College of Medicine, Shandong University, Jinan, Shandong, China.

${ }^{1}$ Jie Zhang, E-mail: 642606603@qq.com ${ }^{1} Y$ uanyuan Xiang, E-mail: 15168889383@126.com 2Xiaokang Ji, E-mail: jxk@sdu.edu.cn ${ }^{3}$ Shaowei Sang, E-mail: sangshaowei1@163.com ${ }^{1}$ Xiang Wang, E-mail: higherwx@163.com ${ }^{1}$ Xiaohui Liu, E-mail: liuxiaohui0315@sina.com ${ }^{4}$ Guangbin Wang, E-mail: cjr.wangguangbin@vip.163.com ${ }^{3}$ Ming Lv, E-mail: Ivming@sdu.edu.cn ${ }^{2}$ Fuzhong Xue, E-mail: xuefzh@sdu.edu.cn ${ }^{1}$ Yifeng Du, E-mail: duyifeng2013@163.com ${ }^{1}$ Qinjian Sun, E-mail: sqj1210@163.com

\section{References}

1. Mathiesen EB, Johnsen SH, Wilsgaard T, Bonaa KH, Lochen ML, Njolstad I: Carotid plaque area and intima-media thickness in prediction of firstever ischemic stroke: a 10-year follow-up of 6584 men and women: the Tromso Study. Stroke 2011, 42(4):972-978.

2. Hollander M, Bots ML, Del Sol Al, Koudstaal PJ, Witteman JC, Grobbee DE, Hofman A, Breteler MM: Carotid plaques increase the risk of stroke and subtypes of cerebral infarction in asymptomatic elderly: the Rotterdam study. Circulation 2002, 105(24):2872-2877.

3. Zhan C, Shi M, Yang Y, Pang H, Fei S, Bai L, Liu B, Tu J, Huo Y, Ning X et al: Prevalence and Risk Factors of Carotid Plaque Among Middle-aged and Elderly Adults in Rural Tianjin, China. Sci Rep 2016, 6:23870.

4. Wang A, Wu L, Liu X, Su Z, Luo Y, Chen S, Li H, Liu X, Tao L, Guo J et al: The prevalence of carotid plaque with different stability and its association with metabolic syndrome in China: The Asymptomatic Polyvascular Abnormalities Community study. Medicine (Baltimore) 2016, 95(34):e4619.

5. Wang W, Wu YF, Zhao D, Yang Y, Lang LR, Wang M, Xie WX, Sun JY, Zhou GH, Shi P et al: [Distribution characteristics and risk factors of carotid atherosclerosis in middle-aged and elderly Chinese]. Zhonghua xin xue guan bing za zhi 2010, 38(6):553-557.

6. Song P, Xia W, Zhu Y, Wang M, Chang X, Jin S, Wang J, An L: Prevalence of carotid atherosclerosis and carotid plaque in Chinese adults: A systematic review and meta-regression analysis. Atherosclerosis 2018, 276:67-73.

7. Song P, Fang Z, Wang H, Cai Y, Rahimi K, Zhu Y, Fowkes FGR, Fowkes FJI, Rudan I: Global and regional prevalence, burden, and risk factors for carotid atherosclerosis: a systematic review, metaanalysis, and modelling study. The Lancet Global Health 2020, 8(5):e721-e729. 
8. Ji X, Leng X-Y, Dong Y, Ma Y-H, Xu W, Cao X-P, Hou X-H, Dong Q, Tan L, Yu J-T: Modifiable risk factors for carotid atherosclerosis: a meta-analysis and systematic review. Annals of Translational Medicine 2019, 7(22):632-632.

9. Nonin S, Iwata S, Sugioka K, Fujita S, Norioka N, Ito A, Nakagawa M, Yoshiyama M: Plaque surface irregularity and calcification length within carotid plaque predict secondary events in patients with coronary artery disease. Atherosclerosis 2017, 256:29-34.

10. Sun Q, Wang Q, Wang X, Ji X, Sang S, Shao S, Zhao Y, Xiang Y, Xue Y, Li J et al: Prevalence and cardiovascular risk factors of asymptomatic intracranial arterial stenosis: The Kongcun Town Study in Shandong, China. Eur J Neurol 2019.

11. Wang X, Zhao Y, Ji X, Sang S, Shao S, Yan P, Li S, Li J, Wang G, Lu M et al: Kongcun Town Asymptomatic Intracranial Artery Stenosis study in Shandong, China: cohort profile. BMJ Open 2020, 10(7): 036454.

12. Lukanova DV, Nikolov NK, Genova KZ, Stankev MD, Georgieva EV: The Accuracy of Noninvasive Imaging Techniques in Diagnosis of Carotid Plaque Morphology. Open access Macedonian journal of medical sciences 2015, 3(2):224-230.

13. Mozzini C, Roscia G, Casadei A, Cominacini L: Searching the perfect ultrasonic classification in assessing carotid artery stenosis: comparison and remarks upon the existing ultrasound criteria. Journal of ultrasound 2016, 19(2):83-90.

14. Thorsson B, Eiriksdottir G, Sigurdsson S, Gudmundsson EF, Bots ML, Aspelund T, Arntzen KA, Mathiesen EB, Gudnason V: Population distribution of traditional and the emerging cardiovascular risk factors carotid plaque and IMT: the REFINE-Reykjavik study with comparison with the Tromso study. BMJ Open 2018, 8(5):e019385.

15. Alsulaimani S, Gardener H, Elkind MS, Cheung K, Sacco RL, Rundek T: Elevated homocysteine and carotid plaque area and densitometry in the Northern Manhattan Study. Stroke 2013, 44(2):457-461.

16. Wityk RJ, Lehman D, Klag M, Coresh J, Ahn H, Litt B: Race and sex differences in the distribution of cerebral atherosclerosis. Stroke 1996, 27(11):1974-1980.

17. Feldmann E, Daneault N, Kwan E, Ho KJ, Pessin MS, Langenberg P, Caplan LR: Chinese-white differences in the distribution of occlusive cerebrovascular disease. Neurology 1990, 40(10):15411545 .

18. Zhang Y, Bai L, Shi M, Lu H, Wu Y, Tu J, Ni J, Wang J, Cao L, Lei P et al: Features and risk factors of carotid atherosclerosis in a population with high stroke incidence in China. Oncotarget 2017, 8(34):57477-57488.

19. Wang C, Lv G, Zang D: Risk factors of carotid plaque and carotid common artery intima-media thickening in a high-stroke-risk population. Brain and behavior 2017, 7(11):e00847.

20. Beckman JA, Creager MA, Libby P: Diabetes and atherosclerosis: epidemiology, pathophysiology, and management. Jama 2002, 287(19):2570-2581.

21. Vinik Al, Erbas T, Park TS, Nolan R, Pittenger GL: Platelet dysfunction in type 2 diabetes. Diabetes care 2001, 24(8):1476-1485. 
22. Ishizaka N, Ishizaka Y, Toda E, Hashimoto H, Nagai R, Yamakado M: Hypertension is the most common component of metabolic syndrome and the greatest contributor to carotid arteriosclerosis in apparently healthy Japanese individuals. Hypertension research : official journal of the Japanese Society of Hypertension 2005, 28(1):27-34.

23. Su TC, Jeng JS, Chien KL, Sung FC, Hsu HC, Lee YT: Hypertension status is the major determinant of carotid atherosclerosis: a community-based study in Taiwan. Stroke 2001, 32(10):2265-2271.

24. Beaussier H, Masson I, Collin C, Bozec E, Laloux B, Calvet D, Zidi M, Boutouyrie P, Laurent S: Carotid plaque, arterial stiffness gradient, and remodeling in hypertension. Hypertension (Dallas, Tex : 1979) 2008, 52(4):729-736.

25. Pletsch-Borba L, Selwaness M, van der Lugt A, Hofman A, Franco OH, Vernooij MW: Change in Carotid Plaque Components: A 4-Year Follow-Up Study With Serial MR Imaging. JACC Cardiovascular imaging 2018, 11(2 Pt 1):184-192.

26. van Dijk AC, Truijman MT, Hussain B, Zadi T, Saiedie G, de Rotte AA, Liem MI, van der Steen AF, Daemen MJ, Koudstaal PJ et al: Intraplaque Hemorrhage and the Plaque Surface in Carotid Atherosclerosis: The Plaque At RISK Study (PARISK). AJNR American journal of neuroradiology 2015, 36(11):2127-2133.

27. Gardener H, Della Morte D, Elkind MS, Sacco RL, Rundek T: Lipids and carotid plaque in the Northern Manhattan Study (NOMAS). BMC Cardiovasc Disord 2009, 9:55.

28. Abi-Ayad M, Abbou A, Abi-Ayad FZ, Behadada O, Benyoucef M: HDL-C, ApoA1 and VLDL-TG as biomarkers for the carotid plaque presence in patients with metabolic syndrome. Diabetes \& metabolic syndrome 2018, 12(2):175-179.

29. Liu Y, Zhu Y, Jia W, Sun D, Zhao L, Zhang C, Wang C, Chen G, Fu S, Bo Y et al: Association between lipid profiles and presence of carotid plaque. Sci Rep 2019, 9(1):18011.

30. Wang W, Huo Y, Zhao D, Liu J, Liang LR, Sun JY, Yang Y, Wang M, Xie WX, Zhou GH et al: [Prediction value of blood lipid levels on newly identified carotid plaque in middle-aged and elderly Chinese population]. Zhonghua xin xue guan bing za zhi 2010, 38(12):1118-1122.

31. Wasserman BA, Sharrett AR, Lai S, Gomes AS, Cushman M, Folsom AR, Bild DE, Kronmal RA, Sinha S, Bluemke DA: Risk factor associations with the presence of a lipid core in carotid plaque of asymptomatic individuals using high-resolution MRI: the multi-ethnic study of atherosclerosis (MESA). Stroke 2008, 39(2):329-335.

32. Eltoft A, Arntzen KA, Hansen JB, Wilsgaard T, Mathiesen EB, Johnsen SH: C-reactive protein in atherosclerosis - A risk marker but not a causal factor? A 13-year population-based longitudinal study: The Troms $\varnothing$ study. Atherosclerosis 2017, 263:293-300.

33. Xu R, Zhang Y, Gao X, Wan Y, Fan Z: High-Sensitivity CRP (C-Reactive Protein) Is Associated With Incident Carotid Artery Plaque in Chinese Aged Adults. Stroke 2019, 50(7):1655-1660.

34. Pleskovič A, Letonja M, Vujkovac AC, Nikolajević Starčević J, Gazdikova K, Caprnda M, Gaspar L, Kruzliak P, Petrovič D: C-reactive protein as a marker of progression of carotid atherosclerosis in subjects with type 2 diabetes mellitus. VASA Zeitschrift fur Gefasskrankheiten 2017, 46(3):187-192. 
35. Weinhold B, Ruther U: Interleukin-6-dependent and -independent regulation of the human C-reactive protein gene. The Biochemical journal 1997, 327 ( Pt 2):425-429.

36. Scirica BM, Morrow DA: Is C-reactive protein an innocent bystander or proatherogenic culprit? The verdict is still out. Circulation 2006, 113(17):2128-2134; discussion 2151.

37. Bian F, Yang X, Zhou F, Wu PH, Xing S, Xu G, Li W, Chi J, Ouyang C, Zhang Y et al: C-reactive protein promotes atherosclerosis by increasing LDL transcytosis across endothelial cells. Br J Pharmacol 2014, 171(10):2671-2684.

38. Chang X, Feng J, Ruan L, Shang J, Yang Y, Sun J, Dang Y, Song Y: Positive correlation between neovascularization degree of carotid atherosclerosis determined by contrast-enhanced ultrasound and level of serum C-reactive protein. VASA Zeitschrift fur Gefasskrankheiten 2015, 44(3):187-194.

39. Moreno PR, Purushothaman KR, Fuster V, Echeverri D, Truszczynska H, Sharma SK, Badimon JJ, O'Connor WN: Plaque neovascularization is increased in ruptured atherosclerotic lesions of human aorta: implications for plaque vulnerability. Circulation 2004, 110(14):2032-2038.

\section{Tables}

Table 1 Demographic and clinical characteristics of participants by carotid plaque $(n=2021)$

\begin{tabular}{|lllll|}
\hline Characteristics & $\begin{array}{l}\text { All } \\
\text { participants }\end{array}$ & $\begin{array}{l}\text { Normal }(\mathrm{n}=1247, \\
61.7 \%)\end{array}$ & $\begin{array}{l}\text { CP } \\
(\mathrm{n}=774,\end{array}$ & $\begin{array}{c}\text { ap- } \\
\text { value }\end{array}$ \\
& $(\mathrm{N}=2021)$ & & $38.3 \%)$ & \\
\hline Age (years), mean (SD) & $57.6(10.4)$ & $54.1(9.0)$ & $63.2(9.9)$ & $<0.001$ \\
\hline Male, n (\%) & $965(47.7)$ & $575(46.1)$ & $390(50.4)$ & 0.061 \\
\hline Hypertension, n (\%) & $1159(57.3)$ & $603(48.4)$ & $556(71.8)$ & $<0.001$ \\
\hline DM, n (\%) & $310(15.3)$ & $142(11.4)$ & $168(21.7)$ & $<0.001$ \\
\hline Dyslipidaemia, n (\%) & $803(39.7)$ & $438(35.1)$ & $365(47.2)$ & $<0.001$ \\
\hline $\begin{array}{l}\text { Total cholesterol (mmol/L), mean } \\
\text { (SD) }\end{array}$ & $5.36(1.00)$ & $5.25(0.93)$ & $5.55(1.07)$ & $<0.001$ \\
\hline Triglyceride (mmol/L), mean (SD) & $1.37(0.93)$ & $1.31(0.88)$ & $1.46(0.99)$ & 0.001 \\
\hline LDL-C (mmol/L), mean (SD) & $2.99(0.68)$ & $2.90(0.64)$ & $3.14(0.72)$ & $<0.001$ \\
\hline HDL-C (mmol/L), mean (SD) & $1.63(0.39)$ & $1.64(0.38)$ & $1.61(0.39)$ & 0.144 \\
\hline Hs-CRP (mg/L), mean (SD) & $1.54(3.50)$ & $1.35(3.56)$ & $1.85(3.37)$ & 0.002 \\
\hline BMI (kg/m²), mean (SD) & $25.12(3.34)$ & $25.33(3.34)$ & $24.79(3.32)$ & $<0.001$ \\
\hline Smoking habits, n (\%) & $718(35.5)$ & $390(31.3)$ & $328(42.4)$ & $<0.001$ \\
\hline Alcohol intaking habits, n (\%) & $783(38.7)$ & $455(36.5)$ & $328(42.4)$ & 0.008 \\
\hline
\end{tabular}


Abbreviations: CP, carotid plaque; DM, diabetes mellitus; LDL-C, low-density lipoprotein cholesterol; HDL-C, high-density lipoprotein cholesterol; BMI, body mass index; hs-CRP, hypersensitive C-reactive protein.

${ }^{\text {aP }}$ comparison between the participants with and without carotid plaque.

Table 2 Association of carotid plaque associated with CRFs ( $n=2021)$

\begin{tabular}{|llll|}
\hline CRFs & $\mathrm{n} / \mathrm{N}$ & \multicolumn{2}{l}{ Odds ratio $(95 \%$ confidence interval) } \\
\cline { 3 - 4 } & & a Model 1 & b \\
& & & \\
\hline Hypertension & $552 / 1155$ & $1.82(1.47-2.25)^{\ddagger}$ & $1.75(1.40-2.19)^{\ddagger}$ \\
\hline DM & $167 / 309$ & $1.72(1.31-2.25)^{\ddagger}$ & $1.41(1.07-1.87)^{\star}$ \\
\hline High total cholesterol $(\geq 6.20 \mathrm{mmol} / \mathrm{L})$ & $195 / 379$ & $1.73(1.35-2.22)^{\ddagger}$ & $1.39(1.00-1.93)^{\star}$ \\
\hline High triglyceride $(\geq 1.80 \mathrm{mmol} / \mathrm{L})$ & $168 / 401$ & $1.30(1.02-1.67)^{\star}$ & $0.94(0.71-1.23)$ \\
\hline High LDL-C $(\geq 3.36 \mathrm{mmol} / \mathrm{L})$ & $271 / 559$ & $1.69(1.35-2.10)^{\ddagger}$ & $1.38(1.03-1.85)^{\star}$ \\
\hline Low HDL-C $(<1.11 \mathrm{mmol} / \mathrm{L})$ & $55 / 115$ & $1.69(1.11-2.57)^{\star}$ & $1.62(1.03-2.55)^{\star}$ \\
\hline High hs-CRP $(\geq 2.0 \mathrm{mmol} / \mathrm{L})$ & $199 / 382$ & $1.65(1.28-2.12)^{\ddagger}$ & $1.55(1.20-2.01)^{\dagger}$ \\
\hline High BMI $\left(\geq 24 \mathrm{~kg} / \mathrm{m}^{2}\right)$ & $470 / 1288$ & $1.10(0.89-1.36)$ & $0.90(0.73-1.13)$ \\
\hline Smoking habits & $327 / 717$ & $1.35(0.98-1.84)$ & $1.37(0.98-1.90)$ \\
\hline Alcohol intaking habits & $327 / 782$ & $1.07(0.80-1.44)$ & $0.96(0.70-1.31)$ \\
\hline
\end{tabular}

Abbreviations: CRFs, cardiovascular risk factors; DM, diabetes mellitus; LDL-C, low-density lipoprotein cholesterol; HDL-C, high-density lipoprotein cholesterol; hs-CRP, hypersensitive C-reactive protein; BMI, body mass index.

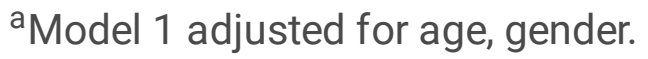

bModel 2 adjusted for age, gender, hypertension, diabetes mellitus, total cholesterol, triglyceride, lowdensity lipoprotein cholesterol, high-density lipoprotein cholesterol, hypersensitive C-reactive protein, body mass index, smoking habits, alcohol intaking habits.

$\mathrm{n} / \mathrm{N}$ indicates number of cases with carotid artery plaque/number of participants.

${ }^{*} \mathrm{P}<0.05$.

${ }^{\dagger} \mathrm{P}<0.01$. 
${ }^{\ddagger} \mathrm{P}<0.001$.

Table 3 Association of single and multiple carotid plaques associated with CRFs ( $n=2014)$

\begin{tabular}{|llll|}
\hline CRFs & $\begin{array}{l}\text { Normal } \\
(\mathrm{n}=1243)\end{array}$ & $\begin{array}{l}\text { Single CP } \\
(\mathrm{n}=319)\end{array}$ & $\begin{array}{l}\text { Multiple CPs } \\
(\mathrm{n}=452)\end{array}$ \\
\hline Reference & OR $(95 \% \mathrm{Cl})^{\mathrm{a}}$ & ${\text { OR }(95 \% \mathrm{Cl})^{\mathrm{a}}}^{-}$ \\
\hline Hypertension & 1.00 & $1.44(1.10-1.90)^{\dagger}$ & $2.28(1.71-3.04)^{\ddagger}$ \\
\hline $\begin{array}{l}\text { High total cholesterol }(\geq 6.20 \\
\text { mmol/L) }\end{array}$ & 1.00 & $1.28(0.89-1.83)$ & $1.65(1.19-2.29)^{\dagger}$ \\
\hline High triglyceride $(\geq 1.80 \mathrm{mmol} / \mathrm{L})$ & 1.00 & $1.46(0.96-2.22)$ & $1.36(0.91-2.03)$ \\
\hline High LDL-C $(\geq 3.36 \mathrm{mmol} / \mathrm{L})$ & 1.00 & $0.90(0.63-1.27)$ & $1.03(0.74-1.44)$ \\
\hline Low HDL-C $(<1.11 \mathrm{mmol} / \mathrm{L})$ & 1.00 & $1.12(0.77-1.63)$ & $1.67(1.17-2.40)^{\dagger}$ \\
\hline High hs-CRP $(\geq 2.0 \mathrm{mmol} / \mathrm{L})$ & 1.00 & $1.43(0.81-2.52)$ & $1.73(1.00-2.99)$ \\
\hline High BMI $\left(\geq 24 \mathrm{~kg} / \mathrm{m}^{2}\right)$ & 1.00 & $1.43(1.03-1.98)^{\star}$ & $1.75(1.29-2.38)^{\ddagger}$ \\
\hline Smoking habits & 1.00 & $1.07(0.80-1.41)$ & $0.81(0.61-1.06)$ \\
\hline Alcohol intaking habits & 1.00 & $1.65(1.08-2.52)^{\star}$ & $1.17(0.78-1.76)$ \\
\hline
\end{tabular}

Abbreviations: $\mathrm{CRFs}$, cardiovascular risk factors; $\mathrm{OR}$, odds ratio; $\mathrm{Cl}$, confidence interval; $\mathrm{CP}$, carotid plaque; DM, diabetes mellitus; LDL-C, low-density lipoprotein cholesterol; HDL-C, high-density lipoprotein cholesterol; hs-CRP, hypersensitive C-reactive protein; BMI, body mass index.

aModel adjusted for adjusted for age, gender, hypertension, diabetes mellitus, total cholesterol, triglyceride, low-density lipoprotein cholesterol, high-density lipoprotein cholesterol, hypersensitive Creactive protein, body mass index, smoking habits, alcohol intaking habits.

${ }^{*} \mathrm{P}<0.05$.

${ }^{\dagger} \mathrm{P}<0.01$.

${ }^{\ddagger} \mathrm{P}<0.001$.

Table 4 Association of regular and irregular carotid plaques associated with CRFs ( $n=2000)$ 


\begin{tabular}{|c|c|c|c|c|c|c|}
\hline \multirow[t]{3}{*}{ CRFs } & \multicolumn{3}{|l|}{ Right } & \multicolumn{3}{|l|}{ Left } \\
\hline & \multicolumn{3}{|c|}{ OR $(95 \% \mathrm{Cl})^{\mathrm{a}}$} & \multicolumn{3}{|c|}{ OR $(95 \% \mathrm{Cl})^{\mathrm{a}}$} \\
\hline & normal & $\begin{array}{l}\text { Regular } \\
\mathrm{CP}\end{array}$ & $\begin{array}{l}\text { Irregular } \\
\mathrm{CP}\end{array}$ & normal & $\begin{array}{l}\text { Regular } \\
\mathrm{CP}\end{array}$ & $\begin{array}{l}\text { Irregular } \\
\mathrm{CP}\end{array}$ \\
\hline Hypertension & 1.00 & $\begin{array}{l}2.05(1.56- \\
2.69)^{\ddagger}\end{array}$ & $\begin{array}{l}1.80(1.12- \\
2.88)^{\star}\end{array}$ & 1.00 & $\begin{array}{l}1.69 \\
(1.31- \\
2.19)^{\ddagger}\end{array}$ & $\begin{array}{l}1.88 \\
(1.20- \\
2.95)^{\dagger}\end{array}$ \\
\hline DM & 1.00 & $\begin{array}{l}1.28(0.94- \\
1.74)\end{array}$ & $\begin{array}{l}1.44(0.88- \\
2.36)\end{array}$ & 1.00 & $\begin{array}{l}1.54 \\
(1.13- \\
2.08)^{\dagger}\end{array}$ & $\begin{array}{l}1.41 \\
(0.88- \\
2.27)\end{array}$ \\
\hline $\begin{array}{l}\text { High total cholesterol } \\
(\geq 6.20 \mathrm{mmol} / \mathrm{L})\end{array}$ & 1.00 & $\begin{array}{l}1.12(0.77- \\
1.62)\end{array}$ & $\begin{array}{l}1.78(0.92- \\
3.46)\end{array}$ & 1.00 & $\begin{array}{l}1.13 \\
(0.78- \\
1.62)\end{array}$ & $\begin{array}{l}1.99 \\
(1.06- \\
3.73)^{\star}\end{array}$ \\
\hline $\begin{array}{l}\text { High triglyceride }(\geq 1.80 \\
\mathrm{mmol} / \mathrm{L})\end{array}$ & 1.00 & $\begin{array}{l}1.05(0.77- \\
1.44)\end{array}$ & $\begin{array}{l}1.05(0.61- \\
1.81)\end{array}$ & 1.00 & $\begin{array}{l}1.01 \\
(0.74- \\
1.38)\end{array}$ & $\begin{array}{l}0.81 \\
(0.47- \\
1.37)\end{array}$ \\
\hline $\begin{array}{l}\text { High LDL-C ( } \geq 3.36 \\
\mathrm{mmol} / \mathrm{L})\end{array}$ & 1.00 & $\begin{array}{l}1.68(1.20- \\
2.34)^{\dagger}\end{array}$ & $\begin{array}{l}1.00(0.53- \\
1.87)\end{array}$ & 1.00 & $\begin{array}{l}1.57 \\
\left(1.13^{-}\right. \\
2.17)^{\dagger}\end{array}$ & $\begin{array}{l}0.97 \\
(0.53- \\
1.76)\end{array}$ \\
\hline $\begin{array}{l}\text { Low HDL-C }(<1.11 \\
\mathrm{mmol} / \mathrm{L})\end{array}$ & 1.00 & $\begin{array}{l}2.25(1.38- \\
3.67)^{\dagger}\end{array}$ & $\begin{array}{l}1.98(0.84- \\
4.64)\end{array}$ & 1.00 & $\begin{array}{l}1.09 \\
(0.65- \\
1.84)\end{array}$ & $\begin{array}{l}1.74 \\
(0.78- \\
3.87)\end{array}$ \\
\hline $\begin{array}{l}\text { High hs-CRP ( } \geq 2.0 \\
\mathrm{mmol} / \mathrm{L})\end{array}$ & 1.00 & $\begin{array}{l}1.49(1.12- \\
1.99)^{\dagger}\end{array}$ & $\begin{array}{l}1.87(1.20- \\
2.91)^{\dagger}\end{array}$ & 1.00 & $\begin{array}{l}1.41 \\
(1.06- \\
1.88)^{*}\end{array}$ & $\begin{array}{l}1.58 \\
(1.03- \\
2.43)^{*}\end{array}$ \\
\hline High BMI $\left(\geq 24 \mathrm{~kg} / \mathrm{m}^{2}\right)$ & 1.00 & $\begin{array}{l}1.00(0.77- \\
1.30)\end{array}$ & $\begin{array}{l}0.82(0.54- \\
1.25)\end{array}$ & 1.00 & $\begin{array}{l}0.77 \\
(0.60- \\
0.99)^{*}\end{array}$ & $\begin{array}{l}0.83 \\
(0.56- \\
1.24)\end{array}$ \\
\hline Smoking habits & 1.00 & $\begin{array}{l}1.27(0.87- \\
1.87)\end{array}$ & $\begin{array}{l}1.62(0.85- \\
3.10)\end{array}$ & 1.00 & $\begin{array}{l}1.21 \\
(0.84- \\
1.75)\end{array}$ & $\begin{array}{l}1.69 \\
(0.92- \\
3.12)\end{array}$ \\
\hline Alcohol intaking habits & 1.00 & $\begin{array}{l}1.13(0.79- \\
1.62)\end{array}$ & $\begin{array}{l}0.69(0.39- \\
1.21)\end{array}$ & 1.00 & $\begin{array}{l}0.85 \\
(0.61- \\
1.20)\end{array}$ & $\begin{array}{l}0.97 \\
(0.57- \\
1.67)\end{array}$ \\
\hline
\end{tabular}

Abbreviations: $\mathrm{CRFs}$, cardiovascular risk factors; $\mathrm{OR}$, odds ratio; $\mathrm{Cl}$, confidence interval; $\mathrm{CP}$, carotid plaque; DM, diabetes mellitus; LDL-C, low-density lipoprotein cholesterol; HDL-C, high-density lipoprotein cholesterol; hs-CRP, hypersensitive C-reactive protein; BMI, body mass index.

aModel adjusted for adjusted for age, gender, hypertension, diabetes mellitus, total cholesterol, triglyceride, low-density lipoprotein cholesterol, high-density lipoprotein cholesterol, hypersensitive C- 
reactive protein, body mass index, smoking habits, alcohol intaking habits.

${ }^{*} \mathrm{P}<0.05$.

${ }^{\dagger} \mathrm{P}<0.01$.

${ }^{\ddagger} \mathrm{P}<0.001$. 